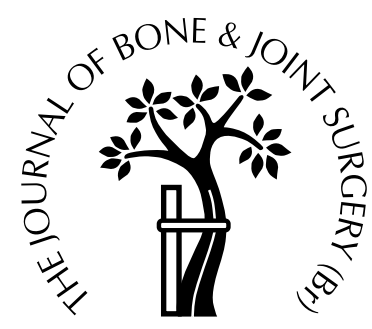

\title{
The relationship between cup design and the radiological signs of aseptic loosening in total hip arthroplasty
}

\author{
U. Müller, E. Gautier, C. Roeder, A. Busato \\ From the Maurice E. Müller Foundation, Bern, Switzerland
}

W e assessed differences in the incidence and appearance of the radiological signs of loosening of the cup for various types of design. This was an observational study based on hip registry data of 15340 patients with 17951 total hip arthroplasties collected over a period of 33 years in 49 hospitals in Central Europe.

The threaded and the press-fit titanium cups showed significantly less aseptic loosening than the other systems. The direction of migration and the frequency of the radiological signs of loosening differed between the cup systems and were time-dependent.

Our findings indicate the superiority of uncemented threaded cups and press-fit titanium cups over other designs of cup.

J Bone Joint Surg [Br] 2003; 83-B:31-6.

Submitted: 23 October 2000; Accepted: 6 June 2002

Aseptic loosening of prosthetic components is the major complication of total hip arthroplasty (THA). It often starts around the cup ${ }^{1}$ and radiological signs of loosening include radiolucencies, migration of the cup, broken screws, broken cement, and a tilted cup. ${ }^{2-5}$ There are many different types of design of cup and methods of fixation used for anchoring the cup in the acetabulum. There is evidence that the design of the cup and the method of fixation have a considerable influence on the incidence of prosthetic failure. ${ }^{6}$ Our aim was to assess the incidence of the radiological signs of loosening of the cup in a large population with respect to diverse designs of cup in primary THA.

U. Müller, MD, MBA, Orthopaedic Surgeon, Senior Research Fellow C. Roeder, MD, Orthopaedic Surgeon

A. Busato, PD, DrMsc, Associate Professor of Clinical Epidemiology Maurice E. Müller Research Centre for Orthopaedic Surgery, University of Bern, Murtenstrasse 35, PO Box 8354, CH-3008 Bern, Switzerland.

E. Gautier, MD, Orthopaedic Surgeon

Service de Chirurgie Orthopèdique, Hôpital Cantonal Fribourg, Fribourg, Switzerland.

Correspondence should be sent to Dr A. Busato.

(C)2003 British Editorial Society of Bone and Joint Surgery doi:10.1302/0301-620X.85B1.12925\$2.00

\section{Patients and Methods}

This was an observational study based on the database of the Maurice E. Müller Centre for Continuing Education and Documentation in Orthopaedic Surgery in Bern, Switzerland. Pre- and postoperative clinical and radiological data were documented using optically readable code sheets from consecutive primary THAs according to the standards of the International Documentation and Evaluation System (IDES). ${ }^{7}$ The following inclusion criteria were used for the study: age older than 20 years at primary surgery, osteoarthritis as the main diagnosis and the availability of multiple follow-up examinations with a complete set of radiographs for the first ten postoperative years. All data were recorded by surgeons on a voluntary basis.

The database yielded 15340 patient records $(49.7 \%$ women, $50.3 \%$ men) with 17951 THAs. The data had been collected between 1967 and 2000 from 49 hospitals in several European countries. The median age of the patients at surgery was 67.1 years; $25 \%$ were younger than 60.5 years and $25 \%$ older than 73.5 years; 2611 (11.7\%) had had bilateral THAs. Previous surgery such as internal fixation after proximal femoral or acetabular fractures, intertrochanteric femoral osteotomy or arthrodesis had been performed in 4.7\%. Classic hybrid systems (cemented stem, uncemented cup) had been used in $47.7 \%$ of operations, totally cemented systems in $24.6 \%$ and totally cementless systems in $14.7 \%$. A reverse hybrid system (cemented cup, uncemented stem) had been used in $13.0 \%$.

Classification of cup systems. There were seven major categories of cup system based on the main properties of the bone-implant interface: cemented polyethylene (PE) cups, press-fit cups (hemispherical, polar flattened press-fit cups), threaded cups, hemispherical cups with screw fixation, reinforcement rings, uncemented threaded PE cups, and expansion shells (Table I). Press-fit cups, hemispherical screw-fixed cups, expansion shells, threaded cups and reinforcement ring systems were made from titanium without a coating. For the threaded uncemented PE cups, a threaded fixation method was used similar to the threaded titanium cups. Coated systems and cups which did not match the seven categories were classified as other systems.

Case definition for acetabular loosening. The IDES follow-up form (form C) provides a radiological assessment 
Table I. Classification and description of cup systems

\begin{tabular}{|c|c|c|c|}
\hline Cup system & Manufacturer & Observations & $\begin{array}{l}\text { Percentage } \\
\text { within system }\end{array}$ \\
\hline \multicolumn{4}{|l|}{ Cemented PE system } \\
\hline PE cup & Sulzer & 4643 & 100.00 \\
\hline \multicolumn{4}{|l|}{ Pressfit system } \\
\hline Press-fit cup, PE with titan mesh (Sulmesh) & Sulzer* & 1630 & 38.97 \\
\hline St Nabor Shell & Sulzer & 1082 & 25.87 \\
\hline FITEK* - shell with screw cones, uncemented & Sulzer & 678 & 16.21 \\
\hline \multirow[t]{2}{*}{ FITEK ${ }^{*}$ - shell with stabilisation fins, uncemented } & Sulzer & 468 & 11.19 \\
\hline & Sulzer & 237 & 5.67 \\
\hline Armor cup, uncemented & Allo Pro* & 88 & 2.20 \\
\hline Other press-fit cups & - & & \\
\hline \multicolumn{4}{|l|}{ Threaded titanium system } \\
\hline Cup CSF Zweymüller & EndoPlus, $\dagger$ Sulzer, Allo Pro* & 2419 & 74.31 \\
\hline Weill Cup & Sulzer & 283 & 8.69 \\
\hline Weill cup CLW & Sulzer & 257 & 7.90 \\
\hline CLW anchorage ring & Sulzer & 236 & 7.25 \\
\hline Other & - & 60 & 1.84 \\
\hline \multicolumn{4}{|l|}{ Fixation with screws system } \\
\hline SL Titanium shell, with flange, PE insert & Sulzer & 1265 & 81.46 \\
\hline SL Titanium shell, with flange and Metasul insert & Sulzer & 148 & 9.53 \\
\hline SL Titanium shell, without flange and PE insert & Sulzer & 62 & 3.99 \\
\hline Other & - & 78 & 5.02 \\
\hline \multicolumn{4}{|l|}{ Reinforcement ring system } \\
\hline Acetabular reinforcement ring & Sulzer & 247 & 53.46 \\
\hline Acetabular reinforcement ring with hook & Sulzer & 215 & 46.54 \\
\hline \multicolumn{4}{|l|}{ PE uncemented system } \\
\hline Endler cup & Allo Pro & 720 & 71.01 \\
\hline RM cup & Mathys $\ddagger$ & 294 & 28.99 \\
\hline \multicolumn{4}{|l|}{ Expansion-shells system } \\
\hline Expansion shell CLS & Sulzer & 1277 & 82.12 \\
\hline Spotorno cementless shell, PE & Sulzer & 189 & 12.15 \\
\hline Spotorno, model unknown & Sulzer & 58 & 3.73 \\
\hline Other & Sulzer & 31 & 1.99 \\
\hline \multicolumn{4}{|l|}{ Other systems } \\
\hline RM cups, double cups, Mecring cups, others & - & 1286 & 100.0 \\
\hline
\end{tabular}

*Sulzer Orthopedics Ltd, Baar, Switzerland

$\dagger$ Mathys Medical Ltd, Bettlach, Switzerland

†Plus Endoprothetik AG, 6343 Rotkreuz, Switzerland

of the changes in bone structure for the period after THA (e.g. radiolucent lines, migration, change in cortical density, ossification and others). ${ }^{8}$ The following definition of acetabular loosening was used: continuous radiolucencies around the cup in zones 1 to 3 according to DeLee and Charnley, ${ }^{9}$ a superior migration $\geqslant 5 \mathrm{~mm}$, severe protrusion or a progressive tilt of the cup, ${ }^{3,4,10}$ and a fracture of the cup or the cement mantle.

Analysis of data. The frequency of radiological loosening was calculated as incidence per patient year ${ }^{11}$ (Tables II and III). Kaplan-Meier ${ }^{12}$ estimates of the cumulative survival percentages are given in Table IV. Maximum likelihood proportional hazard models were used to estimate differences in the incidence of loosening between the types of cup. Cemented PE cups were taken as the reference level for these analyses. The results are given as hazard ratios relative to this reference. Preliminary models indicated confounding effects of age and gender. There were linear effects for age but insignificant effects of the age and cup system interaction or of the gender and cup system interaction. Adjustments for the confounding effects of age and gender were therefore made by respective covariates in the model. Age was included as a continuous variable and interaction terms were not considered in the final model. It was assumed that the baseline hazard functions of loosening of the cup differed between hospitals. An analysis stratified on hospital was therefore evaluated separately. The proportional hazard assumptions (proportional hazard ratios over time) were checked using graphical methods (log-log plots of the survival curves) and the overall fit between the model and data was assessed using an analysis of Cox-Snell residuals. ${ }^{12}$ The standard errors of hazard ratios were adjusted for clustering of the data at the patient level (for patients with both hips replaced). Differences in the migration pattern between cup systems were assessed using chi-squared statistics or, when applicable, by Fisher's exact test. Data were analysed using STATA 7.0 (Stata Corporation, College Station, Texas). The level of statistical significance was set at 0.05 . 
Table II. Distribution of the cup systems and the incidence per patient year of the radiological signs of cup loosening

\begin{tabular}{|c|c|c|c|c|c|c|c|}
\hline \multirow[b]{2}{*}{ Cup system } & \multicolumn{2}{|c|}{ Observations } & \multirow{2}{*}{$\begin{array}{l}\text { Median observation } \\
\text { time (years; range) }\end{array}$} & \multirow{2}{*}{$\begin{array}{l}\text { Number of } \\
\text { loose cups }\end{array}$} & \multirow{2}{*}{$\begin{array}{l}\text { Median time } \\
\text { to first signs } \\
\text { of loosening } \\
\text { (years)* }\end{array}$} & \multirow{2}{*}{$\begin{array}{l}\text { Total patient } \\
\text { years at risk }\end{array}$} & \multirow{2}{*}{$\begin{array}{l}\text { Incidence } \\
\text { per year } \\
(\%)\end{array}$} \\
\hline & Number & $(\%)$ & & & & & \\
\hline Cemented PE & 4643 & 25.87 & $4.21(0.06$ to 26.48$)$ & 442 & 7.59 & 22031.61 & 2.0 \\
\hline Press-fit & 4183 & 23.25 & $1.68(0.09$ to 14.74$)$ & 28 & 2.07 & 11960.14 & 0.2 \\
\hline Threaded titanium & 3255 & 8.66 & $4.72(0.02$ to 16.65$)$ & 46 & 2.17 & 14923.22 & 0.3 \\
\hline Fixation with screws & 1553 & 18.15 & $4.51(0.07$ to 13.71$)$ & 53 & 8.03 & 6169.69 & 0.9 \\
\hline Reinforcement ring & 462 & 2.58 & $3.18(0.23$ to 20.32$)$ & 22 & 5.02 & 1725.80 & 1.3 \\
\hline PE cemented & 1014 & 5.66 & $2.10(0.17$ to 18.98$)$ & 129 & 9.37 & 4818.51 & 2.7 \\
\hline Expansion shells & 1555 & 8.67 & $2.52(0.15$ to 10.65$)$ & 19 & 2.52 & 5177.48 & 0.4 \\
\hline Other & 1286 & 7.16 & 2.08 (0.17 to 28.50$)$ & 76 & 7.79 & 5194.76 & 1.5 \\
\hline Total & 17951 & 100.00 & $2.91(0.02$ to 28.50$)$ & 815 & 7.17 & 72001.23 & 1.1 \\
\hline
\end{tabular}

*median time to the occurrence of first clinical or radiological signs of loosening of the cup

Table III. Incidence per patient year of the radiological signs of loosening of the cup by the decade in which the THA was performed

\begin{tabular}{|c|c|c|c|c|c|c|c|}
\hline \multirow{2}{*}{$\begin{array}{l}\text { Decade of } \\
\text { THA }\end{array}$} & \multicolumn{2}{|c|}{ Observations } & \multirow{2}{*}{$\begin{array}{l}\text { Median observation } \\
\text { time (years; range) }\end{array}$} & \multirow{2}{*}{$\begin{array}{l}\text { Number of } \\
\text { loose cups }\end{array}$} & \multirow{2}{*}{$\begin{array}{l}\text { Median time } \\
\text { to first signs } \\
\text { of loosening } \\
\text { (years) }\end{array}$} & \multirow{2}{*}{$\begin{array}{l}\text { Total patient } \\
\text { years at risk }\end{array}$} & \multirow{2}{*}{$\begin{array}{l}\text { Incidence } \\
\text { per year } \\
(\%)\end{array}$} \\
\hline & Number & $(\%)$ & & & & & \\
\hline Before 1980 & 1313 & 7.32 & $6.91(0.13$ to 28.50$)$ & 280 & 8.41 & 9738.27 & 2.9 \\
\hline 1980 to 1990 & 9302 & 51.84 & 3.77 (0.06 to 18.32$)$ & 434 & 7.43 & 41906.32 & 1.0 \\
\hline After 1990 & 7302 & 40.70 & $2.11(0.02$ to 10.03$)$ & 101 & 2.11 & 20356.63 & 0.5 \\
\hline
\end{tabular}

\section{Results}

The overall incidence of radiological signs of loosening of the cup was $1.1 \%$ per patient year (Table II). A separate analysis for the incidence of loosening of cemented and uncemented systems resulted in an incidence of loosening of $1.7 \%$ for cemented cups and $0.8 \%$ for uncemented cups. The overall incidences, stratified by the decade in which the THA was performed, are given in Table III.

The observed cumulative survival percentage of the cup systems ranged from $95.09 \%$ to $99.35 \%$ for five years and from $75.98 \%$ to $96.94 \%$ for ten years after THA (Table IV). The frequency of the migration patterns and of radiolucencies in loose cups are shown in Tables V and VI. During the first five years after THA superior migration occurred in expansion shell cups, in screw fixation cups, in reinforcement ring systems and in cemented PE cups. Medial migration and radiolucencies were observed in varying degrees during the same period for all cup systems. Radiolucencies were observed around every threaded cup which was classified as loose. Tilting of the cup was observed in all systems during the first five years with the exception of those with screw fixation, uncemented PE cups and reinforcement ring systems (Table V). Migration patterns and radiolucencies were more evenly distributed between the systems between five and ten years after THA (Table VI). The incidence and pattern of frequency of migration and radiolucencies differed significantly between the systems for both periods $(\mathrm{p}<0.0001)$.

The incidence of the radiological signs of loosening based on the design of cup are shown as the incidence per patient
Table IV. Kaplan-Meier estimates of the cumulative survival percentages with $95 \%$ confidence intervals for the cup systems at five and ten years after primary THA

\begin{tabular}{lll}
\hline Cup system & 5 years & 10 years \\
\hline Cemented PE & $96.61(95.87$ to 97.23$)$ & $75.98(73.33$ to 78.42$)$ \\
Press-fit & $99.09(98.50$ to 99.45$)$ & $96.94(93.98$ to 98.45$)$ \\
Threaded titanium & $99.35(98.93$ to 99.61$)$ & $96.75(94.97$ to 97.90$)$ \\
Fixation with screws & $96.35(95.02$ to 97.33$)$ & $93.01(90.27$ to 95.00$)$ \\
Reinforcement ring & $96.40(92.97$ to 98.18$)$ & $82.23(72.04$ to 88.98$)$ \\
PE uncemented & $95.09(92.81$ to 96.66$)$ & $76.99(71.59$ to 81.50$)$ \\
Expansion shells & $98.73(97.71$ to 99.29$)$ & $92.69(84.16$ to 96.71$)$ \\
Other & $96.67(94.80$ to 97.88$)$ & $85.76(80.92$ to 89.46$)$ \\
\hline
\end{tabular}

year in Tables II and III. Differences between systems are given as relative hazard ratios with reference to the cemented PE cups. In this context relative hazard ratios denote the ratio of the hazards of failure for a patient with a specific cup system relative to a patient with a cemented PE cup (Table VII). There were no indications that assumptions for proportional hazard models were violated. The agreement between data and models was satisfactory and the stratified model fitted slightly better than the unstratified model. The results of the stratified model were therefore used for the study. There were no significant effects of gender and age at primary THA.

\section{Discussion}

The aetiology of loosening of the acetabular component is multifactorial. Osteolysis as one of the signs of loosening has 
Table V. Distribution of the radiological signs of loosening of the cup in the first five years after THA

\begin{tabular}{|c|c|c|c|c|c|}
\hline Cup system & Number of hips & $\begin{array}{l}\text { Superior migration } \\
(\%)\end{array}$ & $\begin{array}{l}\text { Medial migration } \\
(\%)\end{array}$ & $\begin{array}{l}\text { Radiolucencies } \\
(\%)\end{array}$ & $\begin{array}{l}\text { Tilt } \\
(\%)\end{array}$ \\
\hline Cemented PE & 98 & 1.02 & 43.88 & 62.24 & 1.02 \\
\hline Press-fit & 19 & 0.00 & 42.11 & 57.89 & 5.26 \\
\hline Threaded titanium & 16 & 0.00 & 68.75 & 37.50 & 6.25 \\
\hline Fixation with screws & 40 & 2.50 & 5.00 & 100.00 & 0.00 \\
\hline Reinforcement ring & 9 & 22.22 & 11.11 & 66.67 & 0.00 \\
\hline PE uncemented & 26 & 0.00 & 61.54 & 38.46 & 0.00 \\
\hline Expansion shells & 12 & 33.33 & 8.33 & 58.33 & 33.33 \\
\hline Other & 21 & 0.00 & 57.14 & 42.86 & 4.76 \\
\hline Total & 241 & 3.32 & 30.00 & 62.24 & 3.32 \\
\hline
\end{tabular}

Table VI. Distribution of the radiological signs of loosening of the cup between five and ten years after THA

\begin{tabular}{|c|c|c|c|c|c|}
\hline Cup system & Number of hips & $\begin{array}{l}\text { Superior migration } \\
(\%)\end{array}$ & $\begin{array}{l}\text { Medial migration } \\
(\%)\end{array}$ & $\begin{array}{l}\text { Radiolucencies } \\
(\%)\end{array}$ & $\begin{array}{l}\text { Tilt } \\
(\%)\end{array}$ \\
\hline Cemented PE & 344 & 4.65 & 27.03 & 84.59 & 2.62 \\
\hline Press-fit & 9 & 11.11 & 33.33 & 44.44 & 11.11 \\
\hline Threaded titanium & 30 & 20.00 & 26.67 & 80.00 & 20.00 \\
\hline Fixation with screws & 13 & 30.77 & 7.69 & 76.92 & 15.38 \\
\hline Reinforcement ring & 13 & 23.08 & 15.38 & 84.62 & 0.00 \\
\hline PE uncemented & 103 & 46.60 & 26.21 & 48.54 & 38.83 \\
\hline Expansion shells & 7 & 14.29 & 42.86 & 85.71 & 28.57 \\
\hline Other & 55 & 18.18 & 52.73 & 56.36 & 5.45 \\
\hline Total & 574 & 15.51 & 28.92 & 74.39 & 10.98 \\
\hline
\end{tabular}

been extensively studied and wear debris is seen as its major cause. ${ }^{13-16}$ Other factors contributing to loosening of the cup include previous surgery, infection, impingement, and failure of the implant. ${ }^{17-20}$ In addition to surgical technique, the physical properties of the material and its surface structure play an important role in loosening of the cup.

Our study focused on the different incidences of the radiological signs of loosening between various cup systems over a long period of time. Patient-related factors, such as age and gender, were treated as 'nuisance' factors in the analysis of the data. The time interval between the appearance of the first radiological signs of loosening and an eventual revision depends not only on the age and level of activity of a patient, ${ }^{21}$ but also on the type of health- care system and on the individual preferences of surgeons. The time to revision may not therefore be a precise indicator of the quality of the cup. We therefore decided to use the incidence of the first radiological evidence of loosening as the outcome variable and not the time to revision.

It could be argued that registry data, based on the voluntary records of surgeons and with little control of follow-up, may be unsuitable for analysis. Our data, however, reflect surgeons who were motivated to document cases early in the development of THA. Nevertheless, there are factors which may bias the results to an unknown extent. The database was originally designed in 1967. At that time it was not thought to be necessary to record radiolucencies around screws. Although this item was initially included in the database, it was defined as a non-compulsory field and consequently was not completed by all surgeons. As a result we could not use the information in the analysis and any interpretation of our data must consider this fact.

Overall incidence of signs of loosening of the cup. Between 1967 and 2000, there was a mean incidence of loosening of the cup of $1.1 \%$ per patient year. The incidence decreased when we stratified the analysis by decade, mostly because of advances in surgical and prosthetic techniques. A mean incidence of $1.1 \%$ appears to be high when compared with those reported in the literature. The Swedish National Hip Arthroplasty Registry reports an overall failure rate of $0.8 \%$ to $1.3 \%$ per year for uncemented implants, depending on the period of follow-up. For cemented systems the reported failure rate was between $0.35 \%$ and $0.84 \%$ per year. $^{22}$ The difference from our data can be explained by several factors. First, we defined failure of the prosthesis as radiological loosening and not as revision. Secondly, our data collection started in 1969, approximately ten years earlier than the Swedish registry, ${ }^{22}$ and the data in Table II indicate an absolute time dependency for loosening of the cup. Finally, the data from the Swedish registry do not differentiate between loosening of the cup and loosening of the stem. The influence of cup design on the radiological signs of loosening. By using the proportional hazards model, our study documents the superiority of the uncemented threaded and press-fit titanium cups over other designs. Hazard ratios were reduced by $84 \%$ for threaded and by $71 \%$ for press-fit cups, compared with cemented PE cups. Expansion shell cups also performed significantly better than cemented PE 
Table VII. Differences between cup systems in the incidence of radiological signs of loosening of the cup, adjusted for age and gender, stratified on hospital

\begin{tabular}{llll}
\hline Cup system & $\begin{array}{l}\text { Hazard } \\
\text { ratio }\end{array}$ & $\begin{array}{l}\text { 95\% confidence } \\
\text { interval }\end{array}$ & P value \\
\hline Cemented PE & $1.00^{*}$ & & \\
Press-fit & $0.29 \dagger$ & 0.16 to 0.54 & 0.000 \\
Threaded titanium & $0.16 \dagger$ & 0.10 to 0.24 & 0.000 \\
Fixation with screws & 0.72 & 0.46 to 1.13 & 0.151 \\
Reinforcement ring & 0.86 & 0.52 to 1.43 & 0.559 \\
PE uncemented & $1.36 \dagger$ & 1.02 to 1.81 & 0.035 \\
Expansion shells & $0.47 \dagger$ & 0.25 to 0.88 & 0.019 \\
Other & 0.98 & 0.73 to 1.31 & 0.882 \\
\hline
\end{tabular}

*cemented PE cups were defined as the reference level

$\dagger$ significant $(\mathrm{p}<0.05)$ difference when compared with the reference level

cups. Reinforcement ring systems and other systems were not significantly different from cemented PE cups. However, the relative hazard ratios of uncemented PE cups indicate a significantly inferior performance than for cemented PE cups.

It is important to note that the cup system which is used is determined not only by the experience and preference of the surgeon but also by the diagnosis. Acetabular reinforcement rings are often used in difficult cases with a poorer prognosis, such as those with reduced bone stock. ${ }^{23-25}$ Although the diagnoses in our study were restricted to osteoarthritis, we cannot exclude bias of the results towards a poorer outcome for acetabular reinforcement rings.

Previous reports have suggested a poor outcome for threaded PE cups. ${ }^{26}$ These were consequently taken from the market and our results support this decision.

Radiolucencies and implant migration were measured by using standard radiological techniques rather than more sophisticated methods. ${ }^{27-29}$ The collection of registry data must be limited to standard methodologies in order to ensure that the data sheets are completed. Only a few cases of loosening were seen with several of the cup systems. The data in Tables V and VI may therefore give only a rough estimate of the migration patterns for loose cups. A relatively conservative definition, however, was used in this study and only cases of marked medial or $5 \mathrm{~mm}$ of superior migration, were considered as loose; $4 \mathrm{~mm}$ is the value given in the literature $^{3,4,10}$ There are no large comparative studies of migration patterns and radiolucent lines in the literature and it is difficult to explain the causes of the different patterns of loosening. Nevertheless, the following conclusions can be drawn:

1) Unstable threaded titanium and cemented PE cups tend to migrate medially during the first five years after THA.

2) Cups with screw fixation have reliable initial fixation with a low incidence of migration and tilt during the five first years after THA. The main feature of the loosening of a screw-fixed cup during the first five years is radiolucency.

3) The patterns of migration of loose cups are more uniform across all systems for periods of follow-up of more than five years.
The median time of observation varied widely between cup systems. This is because the registry is still ongoing and the different cup systems were not introduced into the registry at the same time. It therefore remains difficult to compare accurately the time to the first radiological signs of loosening between the systems. Some comparisons can be made for cup systems with similar observation times, such as cemented PE cups, screw-fixed cups, and threaded cups or between press-fit, expansion-shell cups, and uncemented PE cups (Table II). Despite these limitations, it appears that the signs of loosening occur relatively early for threaded and press-fit cups. Early signs of loosening were also observed for expansion shells when compared with uncemented PE cups and other systems.

We suggest the following explanations for these observations:

1) The press-fit cup, the expansion shell and the uncemented threaded titanium cup systems obtain their primary anchorage by direct mechanical stability which is transformed into a secondary biological stability by bony integration. ${ }^{6,30}$ If this integration process fails because of initial instability, ${ }^{6,31}$ early loosening will occur.

2) Cemented PE cups have good primary mechanical stability. ${ }^{32,33}$ There is, however, no transformation of the fixation principle over time. The initial fixation appears to be stable with modern cementing techniques. Consequently, if the cup fails, it fails late. ${ }^{34}$

3) The hemispherical cup fixed with screws and the reinforcement ring have good primary stability because of the screws. ${ }^{32}$ Bony integration takes place if the fixation is stable. ${ }^{6,31}$ Nevertheless, failure is more frequent than with the press-fit, threaded titanium and expansion-shell cup systems. Good initial fixation with screws may fail as bone remodelling occurs, allowing loosening of the cup, particularly if osseointegration fails to take place. ${ }^{35}$ The screws may hold a loosened cup in position. Major migration will only start after failure of fixation which explains the 'late' failures of screw-fixed cups.

We conclude that the threaded titanium and press-fit cups have a lower incidence of aseptic loosening than PE cups in the long-term. The pattern of migration and the frequency of radiolucencies differ significantly between the various cup systems.

The authors wish to thank Dr Shu-Fang Hsu Schmitz of the Institute of Mathematical Statistics, University of Bern for statistical advice and Edith Röösli for support in data management.

No benefits in any form have been received or will be received from a commercial party related directly or indirectly to the subject of this article.

\section{References}

1. Charnley J. Low friction arthroplasty of the hip: theory and practice. Springer Verlag Berlin, 1979.

2. Greiner B, Braun M, Becker W. Value of the plain roentgen image and arthrography in diagnosis of loosening of cemented hip endoprostheses. Z Orthop Ihre Grenzgeb 1997;135:292-6.

3. Hodgkinson JP, Shelley P, Wroblewski BM. The correlation between the roentgenographic appearance and operative findings at the bone-cement junction of the socket in Charnley low friction arthroplasties. Clin Orthop 1988;228:105-9. 
4. Dihlmann W, Dihlmann SW, Hering L. Alloarthroplasty of the hip joint: radiologic diagnosis of loosening and infection in cemented total endoprostheses. Radiologe 1991;31:496-505.

5. Mjoberg B. Loosening of the cemented hip prosthesis: the importance of heat injury. Acta Orthop Scand Suppl 1986;221:1-40.

6. Thanner J. The acetabular component in total hip arthroplasty: evaluation of different fixation principles. Acta Orthop Scand Suppl 1999;286:1-41.

7. Paterson D. The International Documentation and Evaluation System (IDES). Orthopedics 1993;16:11-4.

8. IDES: Part 1: Total hip arthroplasty. $1^{\text {st }}$ annual meeting, New Orleans. (American Academy of Orthopedic Surgeons AAOS), 1994.

9. DeLee JG, Charnley J. Radiological demarcation of cemented sockets in total hip replacement. Clin Orthop 1976;121:20-32.

10. Brand RA, Pedersen DR, Yoder SA. How definition of "loosening" affects the incidence of loose total hip reconstructions. Clin Orthop 1986;210:185-91.

11. Rothman KJ, S. G. Modern epidemiology. $2^{\text {nd }}$ edition. Philadephia: Lippincott-Raven Publishers, 1998.

12. Klein JP, Moeschberger ML. Survival analysis: techniques for censored and truncated data. Springer-Verlag, New-York, 1997.

13. Schmalzried T, Akizuki K, Fedenko A, Mirra J. The role of access of joint fluid to bone in periarticular osteolysis. J Bone Joint Surg [Am] 1997;79-A:447-52.

14. Willert H, Bertram H, Buchhorn G. Osteolysis in alloarthroplasty of the hip. Clin Orthop 1990;258:95-107.

15. Willert H, Buchhorn G, Göbel D, et al. Wear behaviour and histopathology of classic cemented metal-on-metal hip endoprosthesis. Clin Orthop 1996;329S:160-8.

16. Jasty M, Goetz D, Bragdon C, et al. Wear of polyethylene acetabular components in total hip arthroplasty: an analysis of 128 components retrieved at autopsy or revision operations. J Bone Joint Surg [Am] 1997;79-A:349-58.

17. Garcia-Cimbrelo E, Diaz-Martin A, Madero R, Munera L. Loosening of the cup after low-friction arthroplasty in patients with acetabular protrusion: the importance of the position of the cup. J Bone Joint Surg [Br] 2000;82-B:108-15

18. Kobayashi S, Takaoka K, Tsukada A, Ueno M. Polyethylene wear from femoral bipolar neck-cup impingement as a cause of femoral prosthetic loosening. Arch Orthop Trauma Surg 1998;117:390-1.

19. Journeaux SF, Morgan DA, Donnelly WJ. Poor results of the Freeman uncemented metal-backed acetabular component: five-to-nine-year results. J Bone Joint Surg [Br] 2000;82-B:185-7.

20. Engelbrecht E, von Foerster G, Delling G. Ionogran in revision arthroplasty. J Bone Joint Surg [Br] 2000;82-B:192-9.
21. Dorey F, Amstutz HC. Discrepancies in the orthopaedic literature: why? A statistical explanation. Instr Course Lect 1993;42:555-64.

22. Malchau H, Herberts P, Söderman P, Odén A. Prognosis of total hip replacement: update and validation of results from the Swedish National Hip Arthroplasty Registry 1979-1998. Göteborg University, Sweden, 2000:1-16.

23. Korovessis P, Stamatakis M, Baikousis A, Katonis P, Petsinis G. Mueller roof reinforcement rings: medium-term results. Clin Orthop 1999;362:125-37.

24. Gill TJ, Siebenrock K, Oberholzer R, Ganz R. Acetabular reconstruction in developmental dysplasia of the hip: results of the acetabular reinforcement ring with hook. J Arthroplasty 1999;14:131-7.

25. Gill TJ, Sledge JB, Muller ME. Total hip arthroplasty with use of an acetabular reinforcement ring in patients who have congenital dysplasia of the hip: results at five to fifteen years. J Bone Joint Surg [Am] 1998;80-A:969-79.

26. Volkmann R, Schneider MA, Bretschneider C, Weise K. More failures of uncemented acetabular screw-rings than of cemented polyethylene cups in total hip arthroplasties. International Orthopaedics 1999;23:138-9.

27. Krismer M, Fischer M, Mayrhofer $\mathbf{P}$, et al. A prospective study of the migration of two acetabular components: PCA versus RM cups. Int Orthop 1994;18:23-8.

28. Mjoberg B, Hansson LI, Selvik G. Instability of total hip prostheses at rotational stress: a roentgen stereophotogrammetric study. Acta Orthop Scand 1984;55:504-6.

29. Malchau H, Karrholm J, Wang YX, Herberts P. Accuracy of migration analysis in hip arthroplasty: digitized and conventional radiography, compared to radiostereometry in 51 patients. Acta Orthop Scand 1995;66:418-24

30. Morscher EW. Current status of acetabular fixation in primary total hip arthroplasty. Clin Orthop 1992;274:172-93.

31. Pilliar RM, Lee JM, Maniatopoulos C. Observations on the effect of movement on bone ingrowth into porous-surfaced implants. Clin $\mathrm{Or}$ thop 1986;208:108-13.

32. Perona PG, Lawrence J, Paprosky WG, Patwardhan AG, Sartori M. Acetabular micromotion as a measure of initial implant stability in primary hip arthroplasty: an in vitro comparison of different methods of initial acetabular component fixation. J Arthroplasty 1992;7:537-47.

33. Litsky AS, Pophal SG. Initial mechanical stability of acetabular prostheses. Orthopedics 1994;17:53-7.

34. Ranawat CS, Peters LE, Umlas ME. Fixation of the acetabular component: the case for cement. Clin Orthop 1997;344:207-15.

35. Blümlein H, Cordey J, Schneider U, Rahn B, Perren SM. Langzeitmessungen der Axialkraft von Knochenschrauben in vivo. Z Orthop 1977;115:603-4. 